\title{
Preditores de permanência e evasão em cursos superiores a distância: revisão da literatura
}

\section{Predictors of permanence and dropout in distance higher education: literature review}

\author{
Ludmila de Oliveira Amaral Ferreira ${ }^{1}$ \\ Luanna Cristina de Souza Paternoster ${ }^{2}$ \\ Ronei Ximenes Martins ${ }^{3}$ \\ Estela Aparecida Oliveira Vieira ${ }^{4}$
}

\begin{abstract}
Resumo
$\mathrm{O}$ artigo apresenta estudo de natureza teórica com base em revisão da literatura que objetivou reunir fatores preditivos para a permanência ou a evasão de estudantes matriculados em cursos de graduação a distância. A identificação de tais preditores contribui para que, a partir dos fatores que geram evasão e/ou que favorecem a permanência dos estudantes nos cursos, seja possível planejar ações para aumentar o índice de sucesso na conclusão dos cursos. Os resultados apontaram que mesmo conhecendo os preditores estes não são totalmente eficazes para responder previamente à permanência ou evasão do estudante, mas podem oferecer indicadores para que seja feito um acompanhamento constante destes estudantes. Assim, verificou-se que é relevante conhecer os estudantes, suas características e suas motivações, o ambiente que o cerca e oferecer metodologias de aprendizagem que favoreçam seus estilos de aprender.
\end{abstract}

Palavras-chave: Aprendizagem; Tecnologia Educacional; Educação a Distância; Ensino Superior; Pesquisa Bibliográfica.

\begin{abstract}
The article presents a theoretical study based on a literature review that aimed to gather predictive factors for the permanency or dropout of distance higher education students. The identification of such predictors contributes so that, based on the factors that generate dropout and / or that favor the permanency of students in the courses, it is possible to plan actions to increase the success rate in distance higher education. The results showed that even knowing the predictors, they are not fully effective to respond in advance to the student's permanence

\footnotetext{
${ }^{1}$ Ludmila de Oliveira Amaral Ferreira, mestranda, Ufla, Lavras, MG, Brasil. 1udmila.ferreira1 @estudante.ufla.br

${ }^{2}$ Luanna Cristina de Souza Paternoster, mestranda, Ufla, Lavras, MG, Brasil

luanna.paternoster@estudante.ufla.br

${ }^{3}$ Ronei Ximenes Martins, Doutor, Ufla, Lavras, Mg, Brasil. rxmartins@ufla.br

${ }^{4}$ Estela Aparecida Oliveira Vieira, Pós-Doutoranda, Ufla, Lavras, Mg, Brasil. estela.ap.o.vieira@gmail.com
} 
or dropout, but they can offer indicators for the constant monitoring of these students. Thus, it was found that it is relevant to know students, their characteristics and motivations, the environment that surrounds them and to offer learning methodologies that favor their learning styles.

Keywords: Learning; Educational Technology; Distance Education; Higher Education; Bibliographical Research.

\section{Introdução}

Formar professores para um contexto de protagonismo em inovações educacionais implica em ampliar os ciclos educativos para etapas mais especializadas de preparação para atuação profissional por meio de cursos de pós-graduação. É na pós-graduação que se estabelecem os espaços mais privilegiados para o desenvolvimento da aprendizagem com pesquisa e da pesquisa como modo de ensinar. Nesta perspectiva, o mestrado profissional em educação da UFLA, foi concebido com vistas a formar profissionais da educação aptos à investigarem a complexidade do fenômeno educativo, a interrogarem sua prática pedagógica e a buscar "novos patamares de compreensão dessa prática pelo exercício da pesquisa e de propostas didático-pedagógicas que vão ao encontro de soluções para os problemas vividos" (MARTINS; RIBEIRO, 2015, p. 433)

No âmbito do MPE, a linha de pesquisa Desenvolvimento Profissional Docente, Práticas Pedagógicas e Inovações proporciona investigações acerca de processos de desenvolvimento profissional docente, desde o sistema educacional aos espaços educativos escolares e não escolares e suas potenciais articulações, com ênfase em práticas pedagógicas e inovações. Destaca-se como temática o campo de pesquisa das práticas e inovações pedagógicas, notadamente as mediadas por tecnologias digitais de informação e comunicação (TDIC) e/ou que criem metodologias que permitam inovações para ações e fazeres no contexto da mediação pedagógica. Conquanto seja sempre importante sinalizar que, embora se faça o destaque das práticas, toda prática é indissociável de referencial teórico. Tendo como princípio orientador tais pressupostos, uma das pesquisas que vem sendo desenvolvida com vários estudos, desde 2011, é o olhar crítico para a formação superior proporcionada nos cursos a distância. Notadamente temos pesquisado possíveis preditores para o sucesso e, no outro extremo, para o abandono dos cursos. É neste contexto que apresentamos este artigo de 
revisão da literatura sobre um dos temas mais prementes na atualidade, quando se fala em educação superior.

A cultura digital é vivenciada há pelo menos 2 décadas no cotidiano das pessoas e, nessa vivência, os modos de se relacionar e representar o conhecimento vão se modificando. Essa mudança social e cultural influencia diversos contextos e, um deles é o da Educação, causando interferências nas práticas pedagógicas de ensino e de aprendizagem.

Em função dessas constantes mudanças, de suas influências nas formas educacionais e levando em consideração que a educação é fundamental para o desenvolvimento das pessoas e da sociedade como um todo, o acesso a educação deve ser garantido a todos. Nesse sentido, a Educação a Distância (EaD) é posta como realidade educacional e possibilidade de acesso a direitos instituídos.

Em 2020, sob o ineditismo de uma pandemia (Covid-19) que causou a suspensão temporária das aulas presenciais, a $\mathrm{EaD}$ tem sido colocada em evidência e em constante discussão. Esse novo cenário mostra a sociedade sendo reconfigurada e promovendo mais desconstruções sob a forma como o ensino e a aprendizagem são vistos socialmente (ARRUDA, 2020).

Um dos efeitos dessa epidemia é a percepção de que não é possível pensar uma educação que combata as Tecnologias Digitais de Informação e Comunicação (TDIC) e que em nenhum outro momento elas foram tão estratégicas para a educação como agora, em tempos de Ensino Emergencial a Distância (EEaD). A partir da pandemia, a sociedade precisou se adaptar rapidamente, aos avanços oferecidos pelas TDIC, principalmente no que se refere à forma de "fazer" o ensino-aprendizagem. (MARTINS, 2020; ARRUDA, 2020; DE OLIVEIRA, 2020).

A EaD, entendida como "metodologia apropriada para permitir a reconstituição das relações entre professores-estudantes-conteúdos curriculares, quando elas estão dificultadas por distanciamento geográfico e/ou temporal" (MARTINS, 2020, p. 249), mediada pelos recursos digitais, possibilitava, desde há algum tempo e também neste novo contexto de pandemia, que um número maior de estudantes sejam admitidos em instituições de ensino superior. Mas, apesar da grande oferta de cursos de graduação a distância, do crescimento substancial do número de ingressantes nos últimos anos - de 15,4\% em 2007 para 33,3\% em 2017 (INEP, 2017) - e de suas características como: flexibilidade de local e horário, 
conciliação com outras atividades, acesso geográfico, dentre outras vantagens apresentadas ao aluno, a EaD tem suas particularidades e seus desafios, assim como as outras metodologias.

Mesmo considerando que a evasão é um problema comum em todos os níveis e formatos de oferta de ensino, na $\mathrm{EaD}$ as taxas de evasão se mantêm entre $11 \%$ e $25 \%$ há alguns anos, segundo dados do Censo $\mathrm{EaD}$ (2017), indicando que, por diferentes e múltiplas razões, os cursos de graduação a distância precisam ser analisados quanto aos seus resultados efetivos, tendo em vista os possíveis fatores que geram a evasão, mas também, quanto aos que favorecem a permanência. Dessa forma, faz-se necessário empreender investigações sobre esses fenômenos.

Nesse sentido, diversos pesquisadores, no Brasil e no exterior, têm estudado a evasão e a permanência, sob diversos pontos de vista, partindo de diferentes premissas para justificar o abandono e, em contrapartida, a persistência em cursos de graduação $\mathrm{EaD}$, relacionando-as ao perfil do aluno (BIELSCHOWSKY; MASUDA, 2018; SOUSA; MACIEL, 2016), a fatores intrínsecos e extrínsecos, incluindo desempenho acadêmico (GRAU-VALLDOSERA; MINGUILLÓN, 2014; DA COSTA; GOUVEIA, 2018; MANJARRÉS et al, 2013; MARTINS; HOKARI, 2014; SERAFIM; MARTINS, 2016), a fatores sociodemográficos (CARNEIRO et al, 2014), a metodologias e qualidade do curso (DO SANTOS; GIRAFFA, 2017; RHODEN; ANDRES; RHODENS, 2018), dentre outros fatores. Porém, temos ainda, lacunas a serem preenchidas.

Amparada em discussões teóricas já realizadas o objetivo dessa pesquisa é então reunir fatores preditivos para permanência ou a evasão de estudantes matriculados em cursos de graduação a distância, possibilitando evidenciar, prever e diminuir fatores que influenciam o risco de evasão (TONTINI; WALTER, 2012).

Sendo assim, organizamos o levantamento bibliográfico apresentado neste relato a fim de identificarmos as diferentes abordagens e pontos de vista que compõem o complexo fenômeno da evasão/permanência em cursos superiores ofertados na modalidade EaD.

A partir do conhecimento mais profundo dos aspectos e fatores que envolvem causasefeitos de evasão ou de permanência será possível planejar ações para aumentar o índice de sucesso na conclusão dos cursos. Com efeito, conhecendo possíveis preditores, as Instituições de Ensino Superior (IES) poderão com esses subsídios organizar estratégias e adotar medidas mais estruturadas e eficientes para a permanência, podendo mitigar a evasão que traz prejuízos aos alunos, à comunidade acadêmica, às instituições de ensino e à sociedade. Em 
tempos de COVID-19, todas as formas de conhecermos melhor os fenômenos educacionais ocorridos em superação ao distanciamento geográfico e temporal podem contribuir para a superação das dificuldades provocadas pelo distanciamento individual prolongado que a pandemia está provocando.

\section{Metodologia}

Existem diferentes abordagens para a compreensão de fenômenos complexos relacionados à educação superior. Segundo Martins (2020, p. 243) “o pensar e o fazer na educação, demandam parcimônia quanto aos determinismos e ao estabelecimento de causasefeitos generalizantes" por serem "fenômenos complexos e imateriais, característicos da natureza humana". Nessa perspectiva é necessário observar a produção científica como processo contínuo e dinâmico de exploração e produção do novo conhecimento a partir de subsídios primordiais do que já foi elaborado para o desenvolvimento da ciência (WITTER, 1999).

A avaliação metacientífica sobre o que está sendo produzido na área do fenômeno investigado permite ampliar os horizontes de compreensão, bem como a partir de diferentes pontos de vista e métodos de investigação, formar a visão complexa necessária ao distanciamento do simplismo fragmentador condenado por Edgar Moran (2000). O investimento em trabalhos a partir desta perspectiva pode resultar em informações relevantes que atuam como norteadoras para a ampliação e aprofundamento dos fenômenos educacionais.

Sobre a análise crítica da produção em pesquisa científica, a professora Witter (1999) defende que é a análise metacientífica que permite aprimorar o conhecimento disponível, descobrir tendências e necessidades. A partir desta premissa, o presente trabalho apresenta revisão sistemática da literatura, de caráter teórico-analítico direcionada a trabalhos de pesquisa que tiveram como objeto de estudo a evasão e/ou a permanência de estudantes em cursos de graduação ofertados com metodologia $\mathrm{EaD}$, com o olhar aprofundado para a identificação de possíveis fatores preditivos do fenômeno.

A revisão sistemática foi escolhida como metodologia de pesquisa pois, "propõe uma reconstrução do percurso conceptual e metodológico na escolha de fontes bibliográficas baseado em procedimentos rigorosos e explícitos para que os resultados não sejam 
incompletos, ineficientes ou, em última análise, sem validade científica". (CONTANDRIOPOULOS et al., 2010 citado por RAMOS; FARIA; FARIA, 2014, pág. 3).

Nesta revisão sistemática a busca de artigos foi realizada com o objetivo de encontrar trabalhos que respondessem a nossa questão problema: o que a literatura científica aponta como possíveis influências para evasão e permanência em cursos de graduação a distância? Para tal foi utilizado um protocolo de seleção das pesquisas que apresentamos a seguir.

Os recursos e estratégias para busca e seleção de estudos foram definidos e selecionados com base em cinco itens fundamentais, são eles: (i) fontes de busca no Portal Capes e Google Acadêmico; (ii) idioma português, inglês, espanhol e francês; (iii) palavraschave: Dropout. Distance Education. Permanence. Higher Education, (iv) operador booleano AND e (v) data de publicação entre 2013 e 2019.

Inicialmente foi estabelecido o seguinte critério de busca de pesquisa: todos os trabalhos encontrados a partir das palavras-chave, nos últimos cinco anos, nas duas plataformas.

Foram encontrados 6 relatos de pesquisa no portal Capes e 252 no Google Acadêmico. Em seguida os pesquisadores selecionaram pelo título, resumo e tipo de literatura 38 artigos relacionados sobre a temática utilizando como critério de inclusão artigos que tratam sobre a evasão e/ou permanência em cursos de graduação a distância e como critério de exclusão trabalhos que não são artigos como: livros, teses, dissertações, trabalhos pagos, trabalhos sem resumo e artigos repetidos.

Em uma revisão mais refinada, foi realizada a leitura dos 38 artigos e sem contato entre os pesquisadores foram eliminados 24 artigos por corresponderem parcialmente à temática proposta, uma vez que o protocolo propunha como critério de seleção ter a metodologia de pesquisa descrita com clareza e com métodos e parâmetros para avaliar a evasão e permanência declarados de forma objetiva e em concordância ao objetivo desta pesquisa, restando 14 artigos a serem analisados.

Tabela 1 - Apresentação dos artigos incluídos na revisão

\begin{tabular}{clll}
\hline $\begin{array}{c}\text { Ano de } \\
\text { publicação }\end{array}$ & \multicolumn{1}{c}{ Autor/es } & \multicolumn{1}{c}{ Título da produção } & \multicolumn{1}{c}{ Periódico } \\
\hline $\mathbf{2 0 1 3}$ & Manjarrés-Riesco, Angeles; & $\begin{array}{l}\text { Open issues in educational affective } \\
\text { ecommendations for distance }\end{array}$ & CEUR Proceedings \\
& $\begin{array}{l}\text { Santos, Olga C.; Boticário, Jesus } \\
\text { G.; }\end{array}$ & $\begin{array}{l}\text { learning scenarios } \\
\text { Saneiro, Mar }\end{array}$ & \\
\hline
\end{tabular}




\begin{tabular}{|c|c|c|c|}
\hline 2014 & $\begin{array}{l}\text { Carneiro, Teresa Cristina Janes; } \\
\text { Da Silva, Maria Aparecida; } \\
\text { De Almeida Bizarrio, Fabiana } \\
\text { Pinto }\end{array}$ & $\begin{array}{l}\text { Fatores que afetam a permanência } \\
\text { dos discentes em cursos de } \\
\text { graduação a Distância: um estudo } \\
\text { na Universidade da Integração } \\
\text { Internacional da Lusofonia Afro- } \\
\text { Brasileira }\end{array}$ & $\begin{array}{l}\text { Gestão } \\
\text { Sociedade }\end{array}$ \\
\hline 2014 & Enriquéz, Larisa & $\begin{array}{l}\text { University outreach; a line of work } \\
\text { for enhancing students' academic } \\
\text { identity within distance education } \\
\text { and open universities. }\end{array}$ & $\begin{array}{l}\text { EdMedia } \\
\text { Innovate } \\
\text { Learning. } \\
\text { Association for } \\
\text { the Advancement } \\
\text { of Computing in } \\
\text { Education }\end{array}$ \\
\hline 2014 & $\begin{array}{l}\text { Grau-Valdossera, } \\
\text { Minguíllon, Julià. }\end{array}$ & $\begin{array}{l}\text { Rethinking dropout in online higher } \\
\text { education: The case of the } \\
\text { Universitat Oberta de Catalunya }\end{array}$ & $\begin{array}{l}\text { International } \\
\text { Review of } \\
\text { Research in Open } \\
\text { and Distributed } \\
\text { Learning }\end{array}$ \\
\hline 2016 & 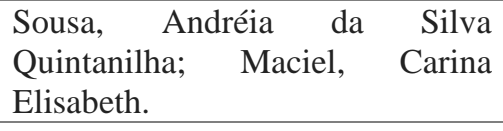 & $\begin{array}{l}\text { Expansão da educação superior: } \\
\text { permanência e evasão em cursos da } \\
\text { Universidade Aberta do Brasil }\end{array}$ & $\begin{array}{l}\text { Educação } \\
\text { Revista }\end{array}$ \\
\hline 2017 & $\begin{array}{l}\text { Barros, Daniela Melaré Vieira et } \\
\text { al. }\end{array}$ & $\begin{array}{l}\text { Estilos de aprendizagem e } \\
\text { permanência no ensino superior a } \\
\text { distância: Licenciatura em } \\
\text { Educação da Universidade Aberta }\end{array}$ & $\begin{array}{lr}\text { Revista } & \text { De } \\
\text { Estudios } & \mathrm{e} \\
\text { Investigación } & \text { En } \\
\text { Psicología } & \mathrm{Y} \\
\text { Educación } & \end{array}$ \\
\hline 2017 & $\begin{array}{l}\text { Hernández, Tomás Huerta; } \\
\text { Velázquez, Sergio Fuenlabrada; } \\
\text { Torres, Verónica Fabiola Chávez }\end{array}$ & $\begin{array}{l}\text { La deserción escolar. Una prioridad } \\
\text { para la educación a distância en el } \\
\text { IPN }\end{array}$ & $\begin{array}{l}\text { Revista Mexicana } \\
\text { de Bachillerato a } \\
\text { Distância }\end{array}$ \\
\hline 2017 & $\begin{array}{l}\text { Kohls dos Santos, Pricila; Martins } \\
\text { Giraffa, Lucia Maria }\end{array}$ & $\begin{array}{l}\text { Permanência na Educação Superior } \\
\text { a distância }\end{array}$ & $\begin{array}{l}\text { Revista } \\
\text { Iberoamericana de } \\
\text { Educación a } \\
\text { Distância }\end{array}$ \\
\hline 2018 & $\begin{array}{l}\text { Bielschowsky, Carlos Eduardo; } \\
\text { Masuda, Masako Oya }\end{array}$ & $\begin{array}{l}\text { Permanência dos Alunos nos } \\
\text { Cursos do Consórcio Cederj }\end{array}$ & $\begin{array}{l}\text { Revista Brasileira } \\
\text { de Aprendizagem } \\
\text { Aberta e a } \\
\text { Distância }\end{array}$ \\
\hline 2018 & Casanova, Joana R. et al & $\begin{array}{l}\text { Factors that determine the } \\
\text { persistence and dropout of } \\
\text { university students }\end{array}$ & Psicothema \\
\hline 2018 & $\begin{array}{l}\text { Da Costa, Oberdan Santos; } \\
\text { Gouveia, Luís Borges }\end{array}$ & $\begin{array}{l}\text { Dropout in distance learning: a } \\
\text { reference model for an integrated } \\
\text { alert system }\end{array}$ & $\begin{array}{l}\text { Proceedings of the } \\
\text { Euro American } \\
\text { Conference on } \\
\text { Telematics and } \\
\text { Information } \\
\text { Systems }\end{array}$ \\
\hline 2018 & $\begin{array}{l}\text { Ferrão, Maria Eugénia; Almeida, } \\
\text { Leandro S. }\end{array}$ & $\begin{array}{l}\text { Multilevel modeling of persistence } \\
\text { in higher education }\end{array}$ & $\begin{array}{lr}\text { Ensaio: } & \text { Avaliação } \\
\text { e } & \text { Políticas } \\
\text { Públicas } & \text { em } \\
\text { Educação } & \end{array}$ \\
\hline 2018 & Mora, Luis Fabian Moncada et al & $\begin{array}{l}\text { Análisis de la triada: integración } \\
\text { académica, permanencia y } \\
\text { dispersión geográfica }\end{array}$ & $\begin{array}{l}\text { RIED. Revista } \\
\text { Iberoamericana de } \\
\text { Educación } \\
\text { Distancia }\end{array}$ \\
\hline 2019 & $\begin{array}{lrr}\text { Rhoden, } & \text { Valmor; } & \text { Andres, } \\
\text { Fernanda } & \text { Sagrilo; } & \text { Rhoden, } \\
\text { Juliana Lima } & \text { Moreira. }\end{array}$ & $\begin{array}{l}\text { Uma análise da evasão discente do } \\
\text { curso de Relações Públicas da } \\
\text { UNIPAMPA-Campus São Borja. }\end{array}$ & $\begin{array}{l}\text { Comunicação \& } \\
\text { Educação }\end{array}$ \\
\hline
\end{tabular}


Fonte: elaborada pelos autores.

A análise dos artigos selecionados foi realizada com base na proposta de categorização de Bardin (2011). Para isso, partimos do pressuposto das multidimensões da evasão e permanência, nas fases de leitura flutuante e codificação. A codificação se deu em função do preditor apresentado e nas unidades de registro. Em seguida, foi realizada a categorização progressiva. Como resultado foram obtidos os eixos (categorias) de agrupamento dos preditores apresentados no quadro 1.

Quadro 1 - Eixos de agrupamento de Preditores de Evasão e Permanência

\begin{tabular}{|c|c|}
\hline \multicolumn{2}{|c|}{$\begin{array}{c}\text { Multidimensionalidade dos } \\
\text { Preditores de Evasão e Permanência }\end{array}$} \\
\hline \multirow{4}{*}{ Categorias } & Afetividade \\
\cline { 2 - 3 } & Características do aluno \\
\cline { 2 - 3 } & Características Sociodemográficas \\
\cline { 2 - 3 } & Fatores relacionados a IES \\
\cline { 2 - 3 } & Características da comunidade acadêmica \\
\cline { 2 - 3 } & Fatores anteriores e posteriores à admissão \\
\cline { 2 - 3 } & Fatores internos e externos \\
\hline
\end{tabular}

Fonte: Elaboração dos autores.

\section{Observações e discussão}

Ao considerarmos que vivemos em uma sociedade em constante transformação e com diversas exigências relacionadas aos modos de trabalho, de se comunicar e se relacionar e, que influenciam diretamente nas formas de ensino e aprendizagem, observamos que a Educação Superior tem enfrentado grandes desafios de mudanças e (re)adequações. O contexto atual de pandemia com fortes restrições à convivência social afeta e afetará profundamente o sistema educacional.

Como em qualquer nível de ensino, os desafios enfrentados são constantes e na esfera do Ensino Superior o desafio perpassa fortemente sobre os aspectos de permanência e evasão de alunos, seja nas graduações presenciais ou a distância.

\footnotetext{
${ }^{5}$ Instituições de Ensino Superior
} 


\section{DEVIR EDUCAÇÃO}

ISSN: 2526-849X

Assim, desenvolver estratégias e ações com o intuito de diminuir as evasões e aumentar as retenções nos cursos de graduação a distância, entender quem é o público da $\mathrm{EaD}$, bem como conhecer e compreender os motivos da evasão e identificar possíveis pontos a serem revistos, é muito relevante para as IES. Essas estratégias também serão válidas para o trabalho da gestão e da equipe de apoio pedagógico e para todos os demais envolvidos no processo, a fim de estruturar linhas de ação mais eficientes contra a evasão e mais favoráveis a permanência dos estudantes, permitindo dessa forma, analisar os resultados obtidos nessa modalidade de ensino, a fim de trabalhar com metodologias mais eficientes e com melhores resultados, (re)assumindo um novo significado.

Neste contexto, as autoras Santos e Giraffa (2017) apontam ser urgente rever novas abordagens e posturas, tanto por parte de educadores quanto dos gestores. Essa iniciativa é plausível na tentativa de promover a permanência de estudantes na EaD. As mesmas autoras, acrescentam ainda que,

[...] identificar o porquê de o aluno ter abandonado contribui para rever políticas e ações, públicas e privadas. No entanto, se pudermos identificar/estabelecer métricas que nos permitam mitigar a evasão teremos uma contribuição de impacto social positivo, uma vez que o custo financeiro e social da evasão impacta todo um projeto de sociedade. (SANTOS; GIRAFFA, 2017, p. 52)

Diante dessas colocações, é possível compreender a multiplicidade de fatores que se correlacionam com a permanência ou evasão dos estudantes de graduação na modalidade a distância. O que fortalece a necessidade de se ter subsídios indispensáveis para produção de análises sobre a realidade universitária nos cursos de graduação EaD.

\section{Os possíveis preditores da evasão}

A evasão na EaD, já como uma realidade constatada nas instituições, públicas ou privadas, mantêm-se em torno de $11 \%$ e 25\%, segundo os dados do censo EaD (ABED, 2017, p. 152). Os fatores envolvidos nesse fenômeno partem de conceitos complexos e variados.

Neste cenário, Santos e Giraffa (2017), discutem que entre trocar de curso e/ou cancelar um curso pode ter múltiplas causas e restringir estes acontecimentos a um simples 
fracasso escolar é desconsiderar diferentes situações pessoais, diferentes contextos e realidades, dentre outras possibilidades.

Tinto (2007), referenciado por Sousa e Maciel (2016), defende que

[...] os estudantes entram na universidade com singularidades em diferentes níveis: pessoais, familiares, habilidades e características acadêmicas, incluindo disposições e intenções com relação à participação nos estudos e em metas pessoais. Essas intenções e os compromissos sofrem, posteriormente, modificações e reformulações de forma contínua por meio de uma série de interações entre o indivíduo, as estruturas, os membros da academia e os sistemas sociais da instituição. (SOUSA; MACIEL, 2016, p. 194).

Nesse sentido, as características pessoais de cada estudante juntamente com o relacionamento com a comunidade acadêmica e com as ações institucionais, podem interferir em sua permanência ou não no curso escolhido.

Manjarrés-Riesco et al (2013) consideram importante a relação entre o estado afetivo do aluno e seu processo de aprendizado. Além de considerar as diferentes características que o aluno apresenta ao pertencer determinados grupos populacionais, o sentimento de inaptidão, o cansaço e a falta de tempo, estão ligados aos sacrifícios pessoais pela busca por aprendizado. E afirmam que a desmotivação é a principal causa de abandono e que a qualidade de comunicações eletrônicas não é suficiente para satisfazer as necessidades de socialização.

Grau-Valldosera e Minguillón (2014) utilizam o termo abandono considerando-o como um fenômeno multidimensional que requer uma análise completa do cenário antes de se buscar as causas. Os autores ainda propõem que definir o que é abandono é tão importante quanto suas causas, para que seja possível conhecer as características do estudante que desistiu, sendo essa definição sensível ao contexto em análise.

Dessa maneira, Grau-Valldosera e Minguillón (2014) analisaram 16 programas da Universidade Aberta da Catalunya e observaram diferenças significativas na taxa de abandono entre esses programas, sendo uma taxa maior nos primeiros semestres, e que alguns motivos para o abandono estão fora do âmbito de um programa único, com a possibilidade de haver razões relacionadas à instituição e/ou as características inerentes ao aluno.

Sousa e Maciel (2016) apresentam uma análise da evasão no Programa Universidade Aberta do Brasil (UAB). A análise dos dados disponíveis no Sistema Universidade Aberta do Brasil (SisUAB) e no Observatório da Vida do Estudante Universitário (OVEU/UFRN) 
resultou na pesquisa cujo objetivo foi conhecer o perfil dos estudantes evadidos no curso de Licenciatura em Física na UAB/Universidade Federal do Rio Grande do Norte (UFRN). As autoras discutem a partir dos dados, sobre a invisibilidade dos estudantes da EaD para a IES e apontam que a evasão não pode mais ser justificada somente pelas "opções" pessoais dos estudantes.

O primeiro passo na direção da compreensão do problema é saber quem são esses alunos, conhecer o perfil socioeconômico e acompanhar os estudantes com potencial preditivo à evasão, criando estratégias e mecanismos para aumentar a permanência desses alunos. Tais estratégias e mecanismos passam pelo envolvimento de professores e coordenadores, e também exigem desenho curricular adequado à modalidade, bem como material didático e infraestrutura eficientes, a fim de garantir o sucesso acadêmico (SOUSA; MACIEL, 2016, p. 200).

Os dados pesquisados pelas autoras indicam que um conjunto de fatores interferem na permanência, ou não, desse estudante na educação superior a distância. Os elementos que determinam essa evasão são, também, confundidos com as dificuldades específicas dessa modalidade. Os resultados da pesquisa indicam que são necessárias políticas de acompanhamento dos estudantes na modalidade a distância, especialmente nos primeiros anos dos cursos, momento em que as pesquisas revelam maior percentual de abandono.

Hernández, Velásquez e Torres (2017) discutem o abandono como um fenômeno multifacetado e histórico que requer a intervenção de todos que participam do processo de ensino e de aprendizagem do aluno sobre a modalidade a distância. A abordagem para analisar as causas foi o "Encontro Acadêmico". Esta reunião foi estruturada em dois momentos: virtual e presencial, realizando um contraste entre as causas da deserção contra linhas de ação e, assim, estabelecendo prioridades. Os autores afirmam que o problema muda de acordo com o perfil da comunidade, do aluno de cada geração. Ressaltam que é necessária uma avaliação sistemática para identificar situações precocemente em risco, além de o comportamento no percurso escolar ter que ser amparado pela análise qualitativa e quantitativa. Por fim, afirmam ser necessário refletir em nível nacional (México) quais são os desafios, indicadores e novas abordagens para abordar a EaD.

Também discutindo sobre a alta taxa de evasão no ensino superior na modalidade a distância, os autores Da Costa e Gouveia (2018) dialogam sobre a evasão nas IES federais como um ônus a sociedade e nas IES particulares como perda de prestígio e risco financeiro. 
Apresentam um modelo de referência de alerta de abandono, já que os índices são motivos de preocupação para administradores da educação e pesquisadores. O "Modelo de Referência para um Sistema Integrado de Alerta (MRSIA)" foi criado pelos autores com base nos modelos teóricos de evasão de JP Bean; JRWylie e JH Park, sendo o último direcionado para as particularidades da $\mathrm{EaD}$, para ser utilizado nas IES a distância com o propósito de prever a intenção de evasão dos estudantes.

O modelo de referência propõe dois parâmetros de análise: preditores anteriores e posteriores à admissão do estudante na graduação (fatores acadêmicos, fatores ambientais e fatores psicológicos); instabilidades dos fatores preditores nos processos de reavaliações (desanexação, retirada, intenção de sair e evasão/permanência). Dentre os fatores preditores, os autores destacam que nenhum fator isolado é responsável pelo abandono do estudante, já que não são independentes e possui influência indireta e direta desses fatores em sua decisão.

Da Costa e Gouveia (2018) ao longo do estudo encontraram duas limitações: 1) a escassez de modelos teóricos que tenham o objetivo de prevenir a evasão e 2) a dificuldade de encontrar trabalhos com foco na prevenção da evasão com abordagem qualitativa, e destacam: "Futuros estudos abrangendo diferentes preditores da evasão são valiosos, pois contribuem para compreensão de fatores que influenciam as intenções dos estudantes em abandonar seus estudos" (p. 5).

Rhoden, Andres e Rhoden (2018), analisando os fenômenos da evasão nos cursos de Relações Públicas da Universidade Federal do Pampa (Unipampa) - Campus São Borja, considerando como instrumentos de estudo os dados de evasão do Sistema de Informações para o Ensino (SIE), abordam algumas sugestões para diminuir a evasão, sendo o eixo central “a aproximação do professor com o aluno". Os autores apontam a necessidade de reorganizar a estrutura curricular, integrando os primeiros semestres do curso com temas inerentes à profissão e aplicando uma metodologia que propicie a articulação com a prática. Com relação à vivência acadêmica, discutem que a evasão também pode ser atenuada por meio de programas de nivelamento, com uma estratégia que tende a amenizar deficiências de escolarização advindas dos níveis fundamental e médio, de modo a acelerar a adaptação dos graduandos na estrutura universitária. Outra solução seria a elaboração de um projeto de apoio pedagógico, com a participação dos docentes do curso.

Os autores Rhoden, Andres e Rhoden (2018) sugerem ainda que é perceptível o maior acesso ao ensino superior no Brasil, mas não há garantia de permanência. Para tanto, é vital o 
debate entre IES e comunidade acadêmica, de modo a apontar algumas alternativas e ampliar o conhecimento da questão para que instituições universitárias consigam ter base reflexiva para criar práticas de retenção de alunos, contribuindo para o desenvolvimento e a manutenção do ensino superior público.

Diante da discussão de tantos autores é possível, confirmar a multidimensionalidade de fatores que envolvem a evasão de alunos e que nenhum fator é isolado. $\mathrm{O}$ abandono perpassa pela característica pessoal dos estudantes, pelos fatores acadêmicos e ambientais. Isto indica que há necessidade de ação das IES desde o primeiro ano de curso, onde os índices de abandono são mais altos.

Na outra extremidade da mesma linha de análise se encontra a multidimensionalidade de fatores que fazem com que o estudante submetido aos mesmos desafios que os que abandonam, persistam e obtenham sucesso. A seguir discutiremos estes condicionantes que, agrupados, resultam na permanência do estudante no curso.

\section{Possíveis preditores da permanência}

A primeira observação que fizemos ao analisarmos os trabalhos sobre a permanência de estudantes em cursos de graduação $\mathrm{EaD}$, foi a de que as emoções e seus efeitos são recorrentes nos relatos de vários pesquisadores. Sobre isto, Enríquez (2014) relaciona a identidade estudantil como processo social de reconhecimento dos eventos externos (sociais, culturais, históricos e acadêmicos) do aluno e sua inserção a partir do sentimento de pertencimento. Enríquez (2014) ainda apresenta algumas atividades de extensão realizadas pela Universidade Nacional Autônoma do México (UNAM) com o objetivo de melhoria no desempenho acadêmico e uma maior taxa de permanência.

As atividades desenvolvidas na UNAM aproximam os estudantes através de um projeto chamado Ser-puma, com o monitoramento de mais de 500 estudantes. Segundo Enriquez (op. cit) o projeto permitiu traçar o perfil acadêmico a fim de buscar soluções específicas para as necessidades específicas com a possibilidade de um aumento significativo na motivação e a oportunidade de fortalecer os laços institucionais entre vários estudantes.

As autoras Carneiro, Almeida e Bizarrio (2014) também com o objetivo de verificar os fatores de permanência analisaram uma amostra composta por 333 discentes do Curso de Graduação em Administração Pública, do Programa de Formação em Administração Pública 
- PNAP, ofertado pela Universidade da Integração Internacional da Lusofonia Afro-Brasileira (UNILAB), em parceria com a Universidade Aberta do Brasil.

Os dados na pesquisa de Carneiro, Almeida e Bizarrio (op.cit) foram obtidos diretamente do sistema acadêmico da universidade e foram analisados apenas os aspectos presentes no sistema e relacionados aos discentes. Dos fatores mais fortemente associados à permanência, dois deles são também associados à condição social: etnia e escola onde estudou o ensino médio. Alunos da etnia branca e alunos oriundos de escola privada evadem mais no curso analisado. Alunos da etnia preta na região em que se situa esse estudo, nordeste do Brasil, podem ter menos oportunidades de frequentar a universidade que não seja pela modalidade de ensino a distância, além de ter menores chances de ocupação mais bem remunerada que não seja pela formação superior.

As autoras da pesquisa na UNILAB destacam que o método aplicado para a análise de dados pode ser replicado em outros cursos e outras instituições de ensino superior, mas os resultados encontrados podem variar em função de outros fatores que também afetam o fenômeno da persistência docente que não foram analisados. Elas sugerem ainda que pesquisas futuras aprofundem as análises buscando interpretar como esses fatores contribuem para a persistência ou a evasão discente, especialmente buscando compreender as características associadas aos polos de apoio presencial que podem estar associadas ao fenômeno analisado.

Em sua pesquisa, Santos e Giraffa (2017) analisaram a permanência sob outra ótica e identificaram quatro fatores com relação direta e uma relação indireta com a permanência quando relacionados os fatores entre si, são eles: Gestão Institucional, Prática Docente, Qualidade do Curso e Dedicação do Estudante. No relato da pesquisa foram destacados, aspectos relacionados ao fator de "dedicação do estudante". Sobre ele, Santos e Giraffa afirmaram que o estudante ao se dedicar mais aos estudos, gera como consequência maior probabilidade do mesmo permanecer nos estudos.

Neste sentido, o aspecto de maior impacto no fator Dedicação do Estudante é o aprofundamento de leituras, o que indica a consciência do estudante de que estudar a distância também é um exercício de autonomia e proatividade. O segundo fator "qualidade do curso", foi confirmado para verificar que quanto melhor a qualidade do ensino oferecido, maior a probabilidade de o estudante permanecer nos estudos. As autoras discutem que, embora a 
pesquisa tenha sido realizada apenas na EaD é possível que fatores verificados e validados possam ser usados em outras categorias de ensino.

Barros et al (2017) aplicaram em estudantes de Licenciatura em Educação da Universidade Aberta, Portugal, um inquérito por questionário, que caracteriza entre outros aspetos a dimensão individual dos estudantes permanentes. Os elementos considerados foram elaborados com base na teoria dos estilos de aprendizagem. Perante os resultados obtidos, que sublinham o estilo de busca e pesquisa no espaço virtual, em detrimento de estilos mais ativos, participativos e orientados para o planejamento de estudos, observou-se a necessidade de desenvolver estratégias pedagógicas que promovam a diversificação de estilos aplicados pelos estudantes nos seus contextos de aprendizagem.

Casanova et at (2018) já consideram que o aumento de estudantes no ensino superior significa um corpo discente mais heterogêneo, dificultando assim a identificação das variáveis que influenciam as decisões dos estudantes de permanecer ou abandonar a universidade. Com o objetivo de analisar a influência dessas variáveis nas decisões dos estudantes, estabelecendo grupos específicos de alunos com base no desempenho, realizaram um estudo com 2.970 estudantes universitários de origem portuguesa, e utilizando a técnica da árvore de decisão conseguiram analisar a relação de dependência de cada variável, sugerindo que a decisão de permanecer ou desistir é particularmente dependente do desempenho acadêmico.

Os autores estabeleceram três grupos (alto, médio e baixo aproveitamento), nos quais diferentes tipos de variáveis atuaram como mediadores: sexo, tipo de curso, o fato de estudar na universidade de primeira escolha dos alunos ou no nível educacional da mãe. Concluíram que os resultados reforçam a importância de intervenções para promover a permanência dos alunos do primeiro ano considerando que habilidades prévias e desempenho acadêmico são decisivo para o sucesso e permanência.

Ferrão e Almeida (2018), relacionaram a permanência com a trajetória escolar anterior do aluno e com as condições de ingresso no ensino superior, controlando as características sociodemográficas dos alunos como sexo e idade, realizaram uma pesquisa com 2.697 alunos do primeiro ano matriculados na Universidade do Minho, uma universidade pública no norte de Portugal. Após a definição do perfil desses alunos, aplicaram a modelagem estatística e concluíram que a admissão do aluno no curso escolhido como a primeira opção é importante para sua persistência. Os resultados também mostraram que os alunos mais velhos e do sexo masculino têm menor probabilidade de persistência. Ainda segundo os autores, "o sucesso é 
moldado por uma variedade de fatores contextuais, incluindo dados demográficos, histórico, características da cultura, estado ou localidade, matriz institucional, recursos disponíveis e políticas existentes" (p. 2).

Ainda, sob o viés da permanência, Bielschowsky e Masuda (2018), analisaram os dados de 53.988 estudantes oriundos de 15 diferentes programas ofertados pela UFRJUniversidade Federal do Rio de Janeiro, através do consórcio CEDERJ- Centro de Ciências e Educação Superior a Distância do Estado do Rio de Janeiro.

Os autores investigaram quais os fatores internos e externos influenciam na persistência dos estudantes ao ingressar em um curso de graduação a distância, com base no modelo de Rovai (2003), que possui 4 dimensões divididas em antes da admissão: características e habilidade do estudante, e após a admissão: fatores internos e externos. Esse modelo foi desenvolvido após a análise dos modelos de Bean e Metzner e de Tinto, e conta com a inserção de outros novos fatores que influenciam na decisão do estudante de permanecer ou não no curso.

A dimensão "características do estudante" leva em consideração as variáveis: idade, etnia, gênero, desenvolvimento intelectual, desempenho acadêmico e preparação acadêmica, enquanto as "habilidades do estudante" são: interação e conhecimento de computadores, gerenciamento do tempo, ler e escrever. Os "fatores internos" estão relacionados ao curso com as variáveis pedagógicas e acadêmicas, como por exemplo a integração social, adaptação ao programa, compromisso pessoal, autoestima, satisfação, necessidade do estudante. Os "fatores externos" consideram: oportunidade, finanças, responsabilidade familiar, dentre outros.

Os autores Bielschowsky e Masuda (2018) em seu estudo relacionaram os fatores de evasão e permanência incluídos apenas em três dimensões de Rovai (2003): características e habilidade do estudante, e fatores externos. Foram identificadas as características dos estudantes com o objetivo de orientar as ações necessárias na busca por maiores índices de permanência dos estudantes.

Relacionando a permanência e algumas características do estudante os autores concluíram que "os mais jovens permanecem menos que os mais velhos" e que "o percentual de permanência das mulheres foi superior ao dos homens em todas as idades" em uma análise geral (BIELSCHOWSKY; MASUDA, 2018, p. 29). Ao analisar a permanência e as habilidades do estudante "o domínio da língua nativa na leitura, compreensão e expressão 
escrita é a base para o aprendizado no ensino a distância" tendo essa correlação uma variação entre os outros programas; “à experiência anterior como um aluno no modo à distância (estes têm uma permanência mais longa)" (BIELSCHOWSKY; MASUDA, 2018, p. 30).

Quando se trata dos fatores externos: "quanto menor a renda, maior a permanência, em uma análise geral", "os resultados que associam permanência ao trabalho não fazem sentido, se não separados por faixa etária. Ao separar, em todas as faixas etárias, o grupo que não trabalha e recebe ajuda financeira da família é aquela que tem uma maior duração”. Sobre o acesso aos recursos de TI: "não ter acesso a esses recursos não aparece como um fator importante para o abandono" (BIELSCHOWSKY; MASUDA, 2018, p. 31).

Considerando que cada programa possui suas particularidades, os autores enfatizam a importância de se realizar uma análise geral dos fatores com muita cautela, pois ao coletar dados de cursos diferentes o pesquisador poderá obter conclusões equivocadas sobre a realidade de uma IES.

Em relação às ações de competência das IES, os fatores internos possuem variáveis importantes na decisão do estudante de permanecer:

[...] ]embora as instituições de ensino superior não possam atuar diretamente nas três dimensões, seus efeitos negativos na permanência podem ser alterados por ações que são de sua competência, como por exemplo a integração social e a integração acadêmica por meio de orientação e acompanhamento da vida acadêmica do aluno, suporte à recuperação de conteúdo e habilidades (Matemática Básica, habilidades de leitura e escrita, proficiência no uso do ambiente virtual de aprendizagem, técnicas de estudo), melhoria no design instrucional, aprimoramento do ambiente virtual capacidade, orientação para inscrição em disciplinas para adaptação à carga de trabalho. (BIELSCHOWSKY; MASUDA, 2018, p. 36).

Mora et al (2019) através de análise da tríade, permanência/evasão, desempenho acadêmico e setor geográfico ratifica a importância da integração acadêmica como fator que fornece mais informações ao explicar a decisão tomada pelos alunos. A partir dos resultados obtidos, os autores concluíram que a integração é o fator que gera o elo mais forte entre o aluno e seu objetivo de se profissionalizar. Com isso, as universidades devem trabalhar estratégias que facilitem a integração, tudo isso nas primeiras semanas de estudo e no primeiro semestre. Da mesma forma, as estruturas curriculares devem favorecer essa integração, de forma que o aluno possa gradualmente se inserir na vida universitária. 
A partir dos fatores descritos na literatura relacionados a permanência é possível verificar que, assim como no caso da Evasão, trata-se de fenômeno multifatorial, sendo identificados como precursores a motivação, as ações da IES relacionadas à gestão institucional e qualidade do curso, as características do aluno como habilidades prévias, dedicação, desempenho acadêmico e perfil sociodemográfico, além da prática docente, que está relacionada a vários desses precursores. Assim como nos preditores de evasão, a literatura mostra que ao analisar os preditores de permanência, alguns autores também sinalizam a importância das ações serem iniciadas nos primeiros anos dos cursos, visto se concentrar neles as maiores pressões para o abandono e, portanto, a maior necessidade de se reforçar os precursores que gerarão a permanência do estudante no curso. A seleção de artigos realizada com base no protocolo proposto e a sua análise, a partir da categorização proposta, permitiu evidenciar alguns preditores que apresentamos de maneira sistematizada no quadro 2 e que foi discutido ao longo do texto.

Considerando as diversas pesquisas realizadas sobre o tema, múltiplos foram os fatores apontados, sendo imprescindível reconhecer que a identificação desses preditores poderá auxiliar em propostas de ação mais eficazes, por parte das IES.

Dentre os fatores identificados, muitos são apontados como influenciadores tanto na discussão para a permanência quanto para evasão. As emoções, por exemplo, aparecem indicando que a desmotivação é forte causa de abandono, enquanto o sentimento de pertencimento contribui para a permanência do aluno. Os preditores evidenciados nas literaturas estudadas foram reunidos no quadro 2.

Quadro 2 - Preditores evidenciados na literatura

\begin{tabular}{|c|c|c|}
\hline Preditor & Descrição & Autor/es \\
\hline Perfil do estudante & $\begin{array}{l}\text { Características inerentes ao aluno; } \\
\text { Mudanças comportamentais e de atitudes } \\
\text { decorrentes de características intrínsecas ao } \\
\text { sujeito. }\end{array}$ & $\begin{array}{l}\text { Manjarrés-Riésco (2013) } \\
\text { Grau-Valldosera; } \\
\text { Minguillón (2014) } \\
\text { Hernández; Velázquez } \\
\text { (2017) } \\
\text { Sousa e Maciel (2016) }\end{array}$ \\
\hline Relativos à Instituição & $\begin{array}{l}\text { Estrutura Curricular; } \\
\text { Nivelamento; } \\
\text { Apoio pedagógico; } \\
\text { Estratégia pedagógica; } \\
\text { Trabalho docente; } \\
\text { Gestão Institucional; } \\
\text { Qualidade do curso. }\end{array}$ & $\begin{array}{l}\text { Grau-Valldosera; } \\
\text { Minguillón (2014) } \\
\text { Rhoden; Andres; Rhoden } \\
\text { (2018) } \\
\text { Barros et al (2017) } \\
\text { Santos; Giraffa (2017) }\end{array}$ \\
\hline
\end{tabular}




\begin{tabular}{|c|c|c|}
\hline $\begin{array}{l}\text { Perfil da Comunidade e do } \\
\text { ambiente acadêmico }\end{array}$ & $\begin{array}{l}\text { As características mudam de acordo com a } \\
\text { comunidade acadêmica e o ambiente } \\
\text { acadêmico; } \\
\text { Influência de fatores acadêmicos, ambientais e } \\
\text { psicológicos; } \\
\text { Influência da trajetória escolar. }\end{array}$ & $\begin{array}{l}\text { Hernández; Velázquez } \\
\text { (2017) } \\
\text { Da Costa; Gouveia (2018) } \\
\text { Ferrão; Almeida (2018) }\end{array}$ \\
\hline Relacionamento e Emoções & $\begin{array}{l}\text { Aproximação entre professor e aluno; } \\
\text { Comunicação eletrônica insuficiente; } \\
\text { Influência da desmotivação e da motivação no } \\
\text { envolvimento dos alunos; } \\
\text { Relação entre o estado afetivo e aprendizado. }\end{array}$ & $\begin{array}{l}\text { Manjarrés-Riésco (2013) } \\
\text { Rhoden; Andres; Rhoden } \\
\text { (2018) } \\
\text { Enriquez (2014) }\end{array}$ \\
\hline $\begin{array}{l}\text { Características } \\
\text { Sociodemográficas }\end{array}$ & $\begin{array}{l}\text { Influência de fatores como: } \\
\text { sexo; idade; classe econômica; situação } \\
\text { ocupacional; setor geográfico }\end{array}$ & $\begin{array}{l}\text { Carneiro; da Silva; } \\
\text { Bizarria (2014) } \\
\text { Mora et al (2019) } \\
\text { Sousa; Maciel (2016) } \\
\end{array}$ \\
\hline Integração Acadêmica & $\begin{array}{l}\text { Gera elo entre o aluno e seu objetivo de se } \\
\text { profissionalizar }\end{array}$ & Mora et al (2019) \\
\hline Fatores internos e externos & $\begin{array}{l}\text { Relacionados à adaptação ao programa, } \\
\text { compromisso pessoal, autoestima, satisfação, } \\
\text { desempenho acadêmico, necessidade do } \\
\text { estudante; } \\
\text { Oportunidade, finanças, responsabilidade } \\
\text { familiar, dentre outros. }\end{array}$ & $\begin{array}{l}\text { Casanova et al (2018) } \\
\text { Carneiro; da Silva e } \\
\text { Bizarria (2014) } \\
\text { Mora et al (2019) } \\
\text { Bielschowsky; Masuda } \\
\text { (2018) } \\
\end{array}$ \\
\hline Curso & $\begin{array}{l}\text { Se o aluno está matriculado no curso de } \\
\text { primeira opção e preferência, isso influência em } \\
\text { sua permanência }\end{array}$ & Ferrão; Almeida (2018) \\
\hline
\end{tabular}

Fonte: Elaboração dos autores.

O que podemos observar é que os fatores envolvidos são complexos e variados. Os principais preditores encontrados nos artigos estavam correlacionados com o perfil do estudante, instituição, perfil da comunidade e do ambiente acadêmico, relacionamento e emoções, características sociodemográficas, integração acadêmica, fatores internos e externos a formação e ao próprio curso em si.

\section{Conclusão}

Este estudo objetivou reunir, a partir de procedimentos de metaciência, preditivos de permanência e evasão em cursos de graduação com metodologia EaD. Considerando as diversas pesquisas realizadas sobre o tema, foram múltiplos. No entanto, com o estudo foi possível visualizar que os fatores envolvidos são de origens diversas, visto que permeados por características pessoais, relações com a instituição, com a equipe mediadora do curso, envolvem noções de pertencimento e laços afetivos. Também se imbricam com a 
infraestrutura ofertada pela IES e a que o estudante tem a disposição. Tudo isso é permeado por questões sócio, econômico e demográficas. Ou seja, é uma conjunção de fatores que quando se entrelaçam levam o estudante a permanecer ou evadir.

Quanto aos instrumentos a serem aplicados para avaliar o perfil do estudante e as possibilidades de prever sua permanência ou não, estes são escassos e agravados por variáveis instáveis que dificultam uma estimativa confiável. Na revisão foi possível encontrar o Modelo de Referência para um Sistema Integrado de Alerta (MRSIA) e o modelo de Rovai, no entanto, estes podem apenas nos dar estimativas e indicativos de acompanhamento de estudantes com determinado perfil. De certa forma, podemos concluir que estes nos apresentam as variáveis a serem observadas em estudos longitudinais futuros.

O que os estudos demonstram é que conhecer os alunos, suas características e suas motivações, o ambiente que o cerca, bem como oferecer-lhes metodologias de aprendizagem que proporcionem adotar estratégias de estudo que lhes favorecem e aos seus estilos de aprender, além de acompanhar de perto a trajetória de cada aluno, são ações que se mostram necessárias, uma vez que a EaD não é produto de consumo do qual o estudante se serve, mas sim uma prática que permite equilíbrio entre as necessidades e habilidades, tanto individuais como as do grupo.

Além dos preditores identificados, também foi constatado em pelo menos quatro pesquisas que as ações para evitar a evasão devem ser reforçados nos primeiros anos de curso, onde existe um grande índice de abandono nos cursos. A partir da identificação dos possíveis preditores, avançaremos com pesquisas de campo que buscarão reforçar evidências de que ações planejadas podem mitigar a evasão e favorecer a permanência dos estudantes em cursos superiores a distância.

\section{REFERÊNCIAS}

ABED - ASSOCIAÇÃO BRASILEIRA DE EDUCAÇÃO A DISTÂNCIA. Censo EAD.BR 2016: relatório analítico da aprendizagem a distância no Brasil. Curitiba: InterSaberes, 2017. Disponível em: www.abed.org.br. Acesso e: 2 maio 2020.

BARDIN, Laurence. Análise de conteúdo. São Paulo: Edições 70, 2011. 
BARROS, Daniela Melaré Vieira et al. Estilos de aprendizagem e permanência no ensino superior a distância: Licenciatura em Educação da Universidade Aberta. Revista De Estudios e Investigación En Psicología Y Educación, Lisboa, p. 58-63, dez, 2017.

BIELSCHOWSKY, Carlos Eduardo; MASUDA, Masako Oya. Permanência dos Alunos nos Cursos do Consórcio Cederj. Revista Brasileira de Aprendizagem Aberta e a Distância. Rio de Janeiro/RJ v. 17, n. 1, p. 1-45, dez, 2018.

BRASIL. MEC. Instituto Nacional de Estudos e Pesquisas Educacionais (Inep). Censo Educação Superior 2017. Divulgação dos principais resultados [Online]. Brasília: Inep, 2018.

CARNEIRO, Teresa Cristina Janes; DA SILVA, Maria Aparecida; DE ALMEIDA BIZARRIA, Fabiana Pinto. Fatores que afetam a permanência dos discentes em cursos de graduação a Distância: um estudo na Universidade da Integração Internacional da Lusofonia Afro-Brasileira. Gestão e Sociedade, Belo Horizonte/MG, v. 8, n. 20, p. 651-669, 2014.

CASANOVA, Joana R. et al. Factors that determine the persistence and dropout of university students. Psicothema, Braga/PT, v. 30, n. 4, p. 408-414, set, 2018.

DA COSTA, Oberdan Santos; GOUVEIA, Luís Borges. Dropout in distance learning: a reference model for an integrated alert system. In: Proceedings of the Euro American Conference on Telematics and Information Systems. ACM, 2018. p. 27.

DE OLIVEIRA, José Palazzo Moreira. É ensinando que se aprende: Ensino Emergencial a Distância. Disponível em: https://www.palazzo.pro.br/Wordpress/e-ensinando-que-seaprende-ensino-emergencial-a-distancia/ Acesso em: 16 maio 2020.

ENRÍQUEZ, Larisa. University outreach; a line of work for enhancing students' academic identity within distance education and open universities. In: EdMedia+ Innovate Learning. Association for the Advancement of Computing in Education (AACE), 2014. p. 255-260.

FERRÃO, Maria Eugénia; ALMEIDA, Leandro S. Multilevel modeling of persistence in higher education. Ensaio: Avaliação e Políticas Públicas em Educação, Rio de Janeiro/RJ v. 26, n. 100, p. 664-683, jul/dez, 2018.

GRAU-VALLDOSERA, Josep; MINGUILLÓN, Julià. Rethinking dropout in online higher education: The case of the Universitat Oberta de Catalunya. International Review of Research in Open and Distributed Learning, v. 15, n. 1, p. 290-308, 2014.

HERNÁNDEZ, Tomás Huerta; VELÁZQUEZ, Sergio Fuenlabrada; TORRES, Verónica Fabiola Chávez. La deserción escolar. Una prioridad para la educación a distancia en el IPN. Revista Mexicana de Bachillerato a Distância, México, v. 9, n. 17, p. 8, 2017.

KOHLS DOS SANTOS, Pricila; MARTINS GIRAFFA, Lucia Maria. Permanência na Educação Superior a distância. RIED: Revista Iberoamericana de Educación a Distancia, Madri/ESP v. 20, n. 1, p. 305-321, 2017. 
MANJARRÉS-RIESCO, Angeles. et al. Open issues in educational affective ecommendations for distance learning scenarios. In: CEUR workshop proceedings. 2013. p. 26-33.

MARTINS, Ronei Ximenes. A COVID-19 e o Fim da Educação a Distância: um ensaio. EmRede-Revista de Educação a Distância, Porto Alegre/RS, v. 7, n. 1, p. 242-256, 2020.

MARTINS, Ronei Ximenes; RIBEIRO, Cláudia Maria. Mestrado profissional em Educação e inovação na prática docente. Revista Brasileira de Pós-Graduação, Brasília/DF, v. 10, n. 20, p. 423, jul. 2015.

MARTINS, Ronei Ximenes; HOKARI, Alberto. Educação a Distância é para Todos? Um Estudo Exploratório sobre Possíveis Preditores do Sucesso Acadêmico. Revista Brasileira de Informática na Educação, [S.1.], v. 22, n. 02, p. 47, ago. 2014. Disponível em: https://www.br-ie.org/pub/index.php/rbie/article/view/2412 . Acesso em: 16 mai 2020.

MORA, Luis Fabian Moncada et al. Análisis de la triada: integración académica, permanencia y dispersión geográfica. RIED. Revista Iberoamericana de Educación a Distancia, Madri/ESP, v. 22, n. 1, p. 271-288, 2019.

MORIN, Edgar. Ciência com consciência. Rio de Janeiro, RJ: Bertrand, 2000.

RAMOS, Altina; FARIA, Paulo M.; FARIA, Ádila. Revisão sistemática de literatura: contributo para a inovação na investigação em Ciências da Educação. Revista Diálogo Educacional, Curitiba/PR, v. 14, n. 41, p. 17-36, jan/abr, 2014.

RHODEN, Valmor; ANDRES, Fernanda Sagrilo; RHODEN, Juliana Lima Moreira. Uma análise da evasão discente do curso de Relações Públicas da UNIPAMPA-Campus São Borja. Comunicação \& Educação, São Paulo/SP, v. 23, n. 2, p. 95-108, jul/dez, 2018.

ROVAI, Alfred P. In search of higher persistence rates in distance education online programs. The Internet and Higher Education, v. 6, n. 1, p. 1-16, 2003.

SERAFIM, Luciana Batista; MARTINS, Ronei Ximenes. Percepção dos cursistas quanto ao desempenho escolar em licenciaturas a distância. Inclusão Social, Brasília/DF, v. 10, n. 1, p. 162-171, abril, 2016.

SOUSA, Andréia da Silva Quintanilha; MACIEL, Carina Elisabeth. Expansão da educação superior: permanência e evasão em cursos da Universidade Aberta do Brasil. Educação em Revista, Belo Horizonte/MG, v. 32, n. 4, p. 175-204, out/dez, 2016.

TONTINI, Gérson; WALTER, Silvana Anita. Pode-se identificar a propensão e reduzir a evasão de alunos? Ações estratégicas e resultados táticos para instituições de ensino superior. Avaliação: Revista da Avaliação da Educação Superior, Campinas/SP, v. 19, n. 1, p. 89110, março, 2014.

WITTER, Geraldina. P. Metaciência e Leitura. In: WITTER, Geraldina P. (Org.). Leitura: Textos e pesquisas. 1. ed. Campinas, SP: Editora Alínea, 1999, p. 13-22. 